\title{
Pregnancy Experiences of First-Time Fathers in Iran:A Qualitative Interview Study
}

\author{
Shahnaz Golian Tehrani ${ }^{1}$; Shahin Bazzazian ${ }^{1, *}$; Nahid Dehghan Nayeri ${ }^{2}$ \\ ${ }_{1}^{1}$ School of Nursing and Midwifery, Tehran University of Medical Sciences, Tehran, IR Iran \\ $2^{2}$ Nursing and Midwifery Care Research Center, School of Nursing and Midwifery, Tehran University of Medical Sciences, Tehran, IR Iran \\ ${ }^{*}$ Corresponding Author: Shahin Bazzazian, School of Nursing and Midwifery, Tehran University of Medical Sciences, Tehran, IR Iran. Tel: +98-2166927171; +98-9122979322, E-mail: shbaz- \\ zazian@yahoo.com
}

Received: May 26, 2013; Revised: January 25, 2014; Accepted: November 27, 2014

\begin{abstract}
Background: Fatherhood, similarly to motherhood, is an important role and responsibility. For accepting this role, one needs to be wellprepared. Awareness of father's experiences of pregnancy can help us to develop plans for the promotion of the role of fatherhood.

Objectives: The purpose of this study was to explore how first time fathers describe their experiences of pregnancy.

Patients and Methods: The data in this qualitative study were collected by individual open-ended interviews in five public health prenatal care clinics in Tehran, Iran, during 2010 - 2011. Participants were 26 Iranian and Moslem first-time fathers living in Tehran, whose partner was in the 32th to 40th week of her normal pregnancy. Qualitative content text analysis was used for analyzing interviews.

Results: Through analysis of fathers' experiences of their wives' pregnancy, four categories, as well as associated subcategories, emerged. The categories include: "Emotional responses to pregnancy, Feeling of change, Accepting the reality and satisfaction, Developing identity as a father." These categories describe the phenomenon of "Transition to fatherhood".

Conclusions: Transition to fatherhood extends beyond only moderate mental and social changes, and may be influenced by cultural background and beliefs. Therefore, caregivers should be aware of fathers' changes and needs during pregnancy, and support them while taking into consideration their culture and beliefs.
\end{abstract}

Keywords:Life Experiences; Fathers; Pregnancy; Iran; Qualitative Research

\section{Background}

Fatherhood, like motherhood, represents an important role, which involves responsibility and, for accepting this role, one needs to be well-prepared. Several issues that arise in the path of transition to the fatherhood phase might have negative effects on the quality of matrimony life (1). In the modern societies, mental and emotional changes of fathers are sometimes neglected and all attention is focused on the mother and her labor (2). The pregnancy period offers a chance for man and woman to adapt with the change to the parenthood phase and familiarize with concepts, such as parenthood parent-child relationship and child raising (3). According to the researchers, there is a direct relationship between the attention given to the importance of fatherhood during pregnancy period and the quality and strength of the relationship between father and child in its embryonic state (4).

The results of several researches indicate that once the participation of fathers in embryonic period and after their child birth is stronger, child growth will occur in a more positive way; this has been demonstrated in improvement of preterm children weight increase in relation to the level of breastfeeding, more efficient learning of language skills, further social growth, higher level of self-esteem, and achieving to higher educational levels
(5). Fatherhood offers a chance for men to strengthen their inner aspects and renew their relationship with their lives (6).

Most of Iranian men have traditional marriages, and having children is important for most of them. The man is the head of a family in Iranian culture and fathers have special respects. In addition, regarding the current entrance of Iranian women into the work field, the role of fathers concerning their children has become more important.

\section{Objectives}

This study was designed to define fathers' experiences of the first pregnancy of their wife in a qualitative manner and in the setting of a real environment.

\section{Patients and Methods}

The design of this study is based on qualitative content analysis with a conventional or traditional approach. Ethical permission to undertake the study was granted from the Research Deputy of Tehran University of Medical Sciences, Tehran, Iran. Five public health prenatal care clinics were selected randomly. The husbands of primi-

Copyright (C) 2015, Iranian Red Crescent Medical Journal. This is an open-access article distributed under the terms of the Creative Commons Attribution-NonCommercial 4.0 International License (http://creativecommons.org/licenses/by-nc/4.0/) which permits copy and redistribute the material just in noncommercial usages, provided the original work is properly cited. 
gravida women were selected using a purposeful sampling method. For this, the researcher looked for health records of pregnant women that presented in the public health prenatal care clinics with their husbands for benefiting from routine prenatal care. The inclusion criteria were being primigravida (first experience of pregnancy), being sure the fetus aliveness, being in 32th to 40th week of pregnancy (for having enough time to develop the feeling fatherhood), adequate mental health of couples, natural labor and couples' willingness to participate in the study. Participants were invited to sit in a comfortable and calm area of the health center and were asked to give their written informed consent. The fathers were allowed to leave the study at any moment they would like. The names of the participants were not recorded.

The interviews were started using an interview guide, which was planned by researchers. Then, interviews progressed according to participants' responses to questions. According to the interview guide, the first questions of the interviews were as follow "How did you feel the first time you heard that your wife is pregnant? What changes does this experience create in you?"

Conventional content analysis was used to analyze the gathered data. First all, conversations were recorded using a voice recorder (MP3 device) and then the words were verbatim typed and analyzed. The manuscripts were scrutinized several times. The codes were extracted from the interviews. Extracted codes followed by the interviews were put together based on their similarity and a name was assigned for them (subcategories), which comprise all associated codes. Then, it was tried to extract categories and themes, which represents data reduction performed by abstraction throughout the research. The interviews continued until no new themes emerged from the data.

\section{Results}

Twenty-six fathers were interviewed between October 2010 and January 2011. Two fathers refused the interview despite meeting the entry criteria. On average, the interviews lasted 25 minutes (range 19-32). Study samples had mean age of 29 years (range 23-34), 55\% of them had high school education, $14 \%$ had higher and $32 \%$ lower educational background. Eighty-six percent of fathers worked in the service sector, $9 \%$ were manual workers and 5\% of them were office workers.

Based on in-depth interviews conducted on the $26 \mathrm{fa}$ thers, the overall number of four categories and 12 subcategories emerged. These categories imply the phenomenon of "transition to fatherhood".

\subsection{Transition to Fatherhood}

Pregnancy period is a time in which fathers experience several mental, psychological, social, and even physical changes to obtain necessary requirements to be a father. Therefore, the, "transition to fatherhood", which in turn includes a set of other categories, emerged as the phenomenon of this study.
Table 1. Analytical Model of First Time Fathers' Experiences of Fatherhood

\begin{tabular}{l}
\hline Transition to Fatherhood, Categories (Subcategories) \\
\hline Emotional responses to pregnancy \\
Wonder and disbelief \\
From comfort to anxiety \\
Happiness \\
Feeling of change \\
Internal changes \\
\hline External changes \\
\hline Accepting the reality and satisfaction \\
\hline The sense of belonging \\
\hline Pay attention \\
\hline Satisfaction \\
\hline Hope \\
\hline Developing identity as a father \\
\hline Initiation of fatherhood feeling \\
\hline Development \\
\hline Attitude toward father's role \\
\hline
\end{tabular}

\subsubsection{Emotional Responses to Pregnancy}

The emotional response, as first response to pregnancy, is a category that consists of feelings such as:

\subsubsection{Wonder and Disbelief}

Several fathers felt wondered while others express feeling of disbelief. For example: “One doesn't know how to react to an event which is happening for the first time in his life" father 26. Or "I didn't believe that until I saw the shape of my wife's abdomen" father 10.

\subsubsection{From Comfort to Anxiety}

A large number of participants mentioned their concern about the health status of their child and wife, e.g. "I worry and stress about my child and wife health status" father 25. Also "Seeing a human being who is a part of me makes me nervous" father 19. Some of the fathers mentioned that their anxiety grows as the mother approaches labor date.

\subsubsection{Happiness}

All fathers stated that they were happy once they heard about their wife pregnancy. For example: "Hearing that my wife is pregnant made me so happy that I was about to cry. I wish I had a pair of wings and fly" father 3.

\subsubsection{Feeling of Change}

Men who experience the fatherhood feeling for the first time in their lives also experience several changes in them- 
selves. These changes can be effective in their preparation to take the paternity role leading to its growth and development. This category was examined in two subcategories.

\subsubsection{Internal Changes}

Once fathers hear about their wife pregnancy they find themselves with different feelings, which start with "waiting", at the beginning, e.g. they state that "I am ready for 9 month waiting" father 9 . This feeling of waiting is sometimes accompanied with other feelings, such as "foresight", "responsibility", and "planning".

\subsubsection{External Changes}

Internal feeling, in turn, leads to several external changes, such as "making further efforts" followed by "higher incomes" which, in consequence, lead to "peace in the family" and "development of love." Also, most participants in this study believed that "once their wife is pregnant they have to work and try doing extra hours" father 19. Also, several responders believed that, ever since their wife is pregnant, they obtain more income. However, several fathers felt no change brought by their wife's pregnancy.

\subsubsection{Accepting the Reality and Satisfaction}

Expectant fathers, who started to accept the pregnancy as real through the first and second trimesters, were able to relate to their unborn baby. According to fathers' statements, during their wife's pregnancy, they had a stronger sense of belonging and paid more attention to their wife and child - which can be really effective in providing the peace and comfort necessary for the mother and child during the pregnancy. This category itself includes four subcategories.

\subsubsection{The Sense of Belonging}

This subcategory included concepts such as "Attachment to the child" and "Attachment to family." One father said "I feel that my attachment to my child has grown over the last days of my wife's pregnancy" father 18. Nevertheless, only few fathers believed that they have no sense of emotional dependence to their child. On the other hand, several fathers mentioned that they felt the presence of their child before it was born and this feeling developed a certain emotional dependence in them. One of them stated that "I really enjoy coming soon at home and be with my wife and child for 24 hours" father 23; this implies their belonging to their family.

\subsubsection{Pay Attention}

This subcategory includes concepts such as "paying attention and expressing love to their wife," "paying attention and expressing love to their child", and "necessity to learn the ways of expressing attention." One of the fathers told that "During the pregnancy period my wife is really touchy and we must really consider it" father 17 . The ma- jority of fathers mentioned that ever since they heard that their wife was pregnant, they were more willing to work at home and help their wife. Moreover, a father mentioned the "since my wife is pregnant, we have less arguments to avoid provoking any damage on our child" father 22 or "during my wife's pregnancy, I used to put my hand on her abdomen and feel my child; I used to talk to him; I used to feel its turning in the abdomen and hear it" father 18. Here the noticeable point is this opinion of several fathers about their need to be aware of the ways to express their love towards their wife and children.

\subsubsection{Satisfaction}

According to the cultural and religious beliefs, most of the fathers were satisfied with their wife's pregnancy and were grateful to God. This satisfaction can affect their behavior towards their wife and child. This subcategory itself consists of feelings such as: "Gratitude, satisfaction with child health, and God willing."

\subsubsection{Hope}

This subcategory includes three feelings: "Faith in God, hopeful view toward life, and divine gift." A father said that "during my wife's pregnancy I totally relied on God" father 8. Also, several fathers mentioned that their hope towards a good life has enhanced ever since their wife became pregnant. Several fathers regard their children as a divine gift: “children are God's gifts” father 18.

\subsubsection{Developing Identity as a Father}

This category implies the feeling and role of fatherhood from the fathers' perspective. This category is further composed of three subcategories:

\subsubsection{Initiation of Fatherhood Feeling}

The initiation of fatherhood feeling can play a significant role in fathers' attention and care for their wife, as well as for the fetus. While there are fathers who believe the feeling of fatherhood for men starts from marriage, others believe this feeling initiates from their wife's pregnancy. Several others consider that the initiation of fatherhood feeling starts once their child is born.

\subsubsection{Feeling of Development}

The changes that fathers experience during the first pregnancy of their wife can result in their growth and development, as several fathers believed in "personality development", "one's personality can really change through the fatherhood" father 4. Others believed in "satisfying the feeling of need for fatherhood," as they state "every man look for the feeling of fatherhood; all men really wish for someone who calls them daddy" father 3. Besides, several participants believed in "feeling the integrity of the family through their wife's pregnancy". All these concepts can somehow imply fathers' development. 


\subsubsection{Attitude Toward Father's Role}

Fathers manifest an attitude toward their fatherhood role, which can affect their behaviors. Several of these attitudes are: "Building their child future," "a matter of safekeeping which should be passed through the generations and be delivered to the children," "respect and caring to the mother and child," and "family disintegration in absence of the father." For example: "Once you deliver emotions and sense of responsibility from your father, you are obliged to keep it in yourself and transfer it to the future generation, which is your children" father 26. Besides, number of fathers believed in the upbringing aspects of fatherhood in the family: "The father's duty is presenting a real human to the society" father 4 . However, the majority of participants believed that the father is responsible for the financial issues of the family whereas children rising represents the mothers' duty. Also, a father believed that the mother's role is more important than that of father and he mentioned that: "The paradise is under mothers' feet" father 15 . Several fathers mentioned differences between fatherhood and motherhood, arguing that "the difference between fatherhood and motherhood resides in their duties, rather than their feelings toward their children" father 25. It seems that the perception of fatherhood meaning can play a key role in the performance of paternity responsibilities.

\section{Discussion}

Concepts placed in the "Emotional responses to pregnancy" category are also found in other researches, e.g. "wonder" $(7,8)$ "disbelief" $(7,9)$, "happiness" $(7,8)$, “comfort and anxiety" $(7,8,10,11)$. These emotional responses were not the same in all fathers and even changed during the different months of pregnancy, as wonder and disbelief were present in the first months of pregnancy, while anxiety registered a constant growth, reaching to the labor date; in this regard the results in this study were similar to those of Finnbogadottir et al. (8) and Barclay et al. (7).

About the category of "Accepting the reality and satisfaction”, Finnbogadottir et al. (8) reported similar results concerning fathers' emotional dependence to their family and child. Besides, Habib and Lancaster (4) and Henwood and Procter (12) reported several similar findings on the sense of belonging towards their child and family.

In the present study, several fathers addressed their need to learn "the ways to express their paying attention." As the findings of the research conducted by Steen, Downe, Bamford, and Edozien (13) showed, fathers are not able to support their wife in a successful pregnancy, enjoyable labor, and to achieve a positive parental experience unless they are properly focused on taking their responsibility. In addition, the research conducted by Backstrom and Hertfelt Wahn (14) found that, if fathers are emotionally neglected, they will feel as if they are helpless and this would endanger their supportive role toward their wife. In this regard, a research conducted by Wahn (15) also reveals that fathers who efficiently play their paternity role can have a positive effect on the labor process.

The concept of "Developing identity as a father," has not been fully discussed in the similar studies. Understating the time in which a man feels paternity has a significant role in determining the beginning of "fatherhood transition period," which is also a point that has been neglected in previous studies. Iranian men are determined to make family bonds as strong as possible and having a child, not only satisfy their need for being a father, yet also makes them feels as if their family is complete and integrated, which contributes to their personality development. This point can distinguish the present study form the previous. Also, the perspective of Iranian men regarding the role of the father makes this research unique, since this attitude originates from the Iranian culture, traditions, and conventions, as the majority of fathers believed that they have learnt the paternity role from their fathers and they should transfer it to their children, as the future fathers. Generally, it is very common for traditional families that their children copy their fathers' behavior $(16,17)$ and this is exactly what was observed in this present study.

The findings of this research imply that the pregnancy period offers a chance for men to experience novel feelings and changes and shift themselves from manhood to fatherhood, achieving the main theme of this study, the "transition to fatherhood." The analytical review of Genesoni and Tallandini (18), conducted on researches conducted from 1989 to 2008 on the "transition to fatherhood" showed that the pregnancy period is the most stressful time for men $(10,11,19)$. This is due to this fact that they are subjected to several psychological changes during this period (10). Fathers, like mothers, need to deliver support, education, and guidance, conclusion which has also been reported by Chalmers and Meyer (20). Moreover, the research performed by Sevil and Ozkan (21) revealed that fathers do not pay sufficient attention during their wife's pregnancy and it is very important that to support them and stimulate their motivation to prepare themselves for this new period of their life. The findings of Deave and Johnson (22) demonstrated that adequately preparing new fathers for parenthood is important, and healthcare givers can contribute to this by involving and supporting new fathers.

According to the findings of Li et al. (23), self-efficacy theory educational programs are effective in reducing fathers' stress. Health care service givers play the key role and they can examine fathers' characteristics through holding educational classes.

The fathers who participated in this research were among those who were attending in health centers with their wives for their pregnancy care. This might be interpreted as maybe the perspective of these fathers is different from that of men who do not accompany their wife 
in the care process. To solve this limitation, we suggest conducting other studies with different setting; for example in fathers' workplaces. Besides, since the fathers who participated in this research were all from Teheran, which is a large metropolis and its dominant culture may differ from other towns or villages, it is probable that the views of fathers from other locations are different from the findings of this research, and this should be investigated by conducting further studies.

\section{Acknowledgements}

This research has been supported by Tehran University of Medical Sciences, Tehran, Iran and the Health Services grant 10482-28-01-89. We are grateful to fathers who participated in the study.

\section{References}

1. McVeigh CA, Baafi M, Williamson M. Functional status after fatherhood: an Australian study. J Obstet Gynecol Neonatal Nurs. 2002;31(2):165-71.

2. Fagerskiold A. A change in life as experienced by first-time fathers. Scand J Caring Sci. 2008;22(1):64-71.

3. Deave $\mathrm{T}$, Johnson $\mathrm{D}$, Ingram J. Transition to parenthood: the needs of parents in pregnancy and early parenthood. BMC Pregnancy Childbirth. 2008;8:30.

4. Habib C, Lancaster S. The transition to fatherhood: Identity and bonding in early pregnancy.J Theor Res and Practice About Men as Fathers. 2006;4(3):235-53.

5. Garfield CF, Isacco A. Fathers and the well-child visit. Pediatrics. 2006;117(4):e637-45.

6. Freitas Wde M, Silva AT, Coelho Ede A, Guedes RN, Lucena KD, Costa AP. Paternity: social responsibility of man's role as provider. Rev Saude Publica. 2009;43(1):85-90.

7. Barclay L, Donovan J, Genovese A. Men's experiences during their partner's first pregnancy: a grounded theory analysis. Aust J Adv Nurs. 1996;13(3):12-24.

8. Finnbogadottir H, Crang Svalenius E, Persson EK. Expect- ant first-time fathers' experiences of pregnancy. Midwifery. 2003;19(2):96-105.

9. Jordan PL. Laboring for relevance: expectant and new fatherhood. Nurs Res.1990;39(1):11-6.

10. Condon JT, Boyce P, Corkindale CJ. The First-Time Fathers Study: a prospective study of the mental health and wellbeing of men during the transition to parenthood. Aust N Z J Psychiatry. 2004;38(1-2):56-64.

11. Hallgren A, Kihlgren M, Forslin L, Norberg A. Swedish fathers' involvement in and experiences of childbirth preparation and childbirth. Midwifery. 1999;15(1):6-15.

12. Henwood K, Procter J. The 'good father': reading men's accounts of paternal involvement during the transition to first-time fatherhood. Br J Soc Psychol. 2003;42(Pt 3):337-55.

13. Steen M, Downe S, Bamford N, Edozien L. Not-patient and not-visitor: a metasynthesis fathers' encounters with pregnancy, birth and maternity care. Midwifery. 2012;28(4):362-71.

14. Backstrom C, Hertfelt Wahn E. Support during labour: first-time fathers' descriptions of requested and received support during the birth of their child. Midwifery. 2011;27(1):67-73.

15. Wahn EH, Nissen E. Sociodemographic background, lifestyle and psychosocial conditions of Swedish teenage mothers and their perception of health and social support during pregnancy and childbirth. Scand J Public Health. 2008;36(4):415-23.

16. Anderson AM. The father-infant relationship: becoming connected. J Soc Pediatr Nurs. 1996;1(2):83-92.

17. Draper J. Men's passage to fatherhood: an analysis of the contemporary relevance of transition theory. Nurs Inq. 2003;10(1):66-77.

18. Genesoni L, Tallandini MA. Men's psychological transition to fatherhood: an analysis of the literature, 1989-2008. Birth. 2009;36(4):305-18.

19. Buist A, Morse CA, Durkin S. Men's adjustment to fatherhood: implications for obstetric health care. J Obstet Gynecol Neonatal Nurs. 2003;32(2):172-80.

20. Chalmers B, Meyer D. What men say about pregnancy, birth and parenthood.J Psychosom Obstet Gynaecol.1996;17(1):47-52.

21. Sevil U, Ozkan S. Fathers' functional status during pregnancy and the early postnatal period. Midwifery. 2009;25(6):665-72.

22. Deave T, Johnson D. The transition to parenthood: what does it mean for fathers? JAdv Nurs. 2008;63(6):626-33.

23. Li HT, Lin KC, Chang SC, Kao CH, Liu CY, Kuo SC. A birth education program for expectant fathers in Taiwan: effects on their anxiety. Birth. 2009;36(4):289-96. 